\title{
Numerical study of mobilized friction along embedded catenary mooring
}

\section{chains}

\author{
Sun, C., Feng, X., Neubecker, S.R., Randolph, M.F., Bransby, M.F., Gourvenec, S.
}

\section{ABSTRACT}

Understanding the soil resistance along an embedded anchor chain is imperative for efficient and economic design of an overall mooring system as it determines the magnitude and direction of the load at the padeye of the anchor. The tensioning process of an embedded chain for catenary moorings was modeled using a coupled Eulerian-Lagrangian (CEL) finite element approach simulating the large deformations of the chain as it cuts through the soil to form an inverse catenary. The analyses reveal that the configuration of the embedded chain and the relationship between tension and chain angle at the padeye show excellent agreement with previously published analytical predictions. However, the ratio of the tension at the padeye to that at the mudline obtained from CEL is significantly higher than the theoretical values, mainly due to partial mobilization of the frictional soil resistance along the length of the chain. The CEL results indicate that the partial mobilization is a result of the combined-loading effect during failure of the soil around the embedded chain as it cuts through the seabed, in contrast with the conventional assumption that the ultimate frictional and normal soil resistances are mobilized simultaneously. A new design approach is proposed for calculating the local equivalent coefficient of friction based on the yield locus for a deeply embedded chain and the normality rule.

Keywords: Anchor chain; catenary mooring; chain-soil interaction; coupled EulerianLagrangian; finite element analysis

No. of words (without abstract and references): 5917

No. of tables:

No. of figures: 
$23{ }^{1}$ Chao SUN

24 Centre for Offshore Foundation Systems

25 Oceans Graduate School

26 University of Western Australia

2735 Stirling Highway, Crawley

28 Perth, WA 6009

29 Australia

30 Tel: +61 469743231

31 Fax: +61 864881044

32 Email: chao.sun@research.uwa.edu.au

${ }^{2}$ Xiaowei FENG, Ph.D.

Centre for Offshore Foundation Systems

Oceans Graduate School

University of Western Australia

35 Stirling Highway, Crawley

Perth, WA 6009

Australia

Email: xiaowei.feng@uwa.edu.au

\section{${ }^{3}$ Steven R. NEUBECKER, Ph.D.}

Centre for Offshore Foundation Systems

Oceans Graduate School

University of Western Australia

35 Stirling Highway, Crawley

Perth, WA 6009

Australia

Email: steven.neubecker@uwa.edu.au

\section{${ }^{4}$ Mark F. RANDOLPH, Ph.D.}

Centre for Offshore Foundation Systems

Oceans Graduate School

University of Western Australia

35 Stirling Highway, Crawley

Perth, WA 6009

61 Australia

62 Email: mark.randolph@uwa.edu.au

${ }^{5}$ Mark Fraser BRANSBY, Ph.D.

66 Centre for Offshore Foundation Systems

67 Oceans Graduate School

68 University of Western Australia

6935 Stirling Highway, Crawley

70 Perth, WA 6009

71 Australia

72 Email: fraser.bransby@uwa.edu.au 
74 'Susan GOURVENEC, Ph.D.

75 School of Engineering

76 Faculty of Engineering and Physical Sciences

77 University of Southampton, Southampton, UK

78 Email: Susan.Gourvenec@southampton.ac.uk 


\section{INTRODUCTION}

Buoyant offshore structures, which provide a variety of functions across the offshore sector, require a mooring system and anchor to keep station. Offshore anchors vary in configuration and operational mode but all generally have a mooring line attachment point, or padeye, below the mudline, with a section of the chain embedded in the soil (Randolph and Gourvenec 2011). For a catenary mooring line applying a horizontal load at the seabed, the embedded chain will form an 'inverse catenary’ in the soil to maintain equilibrium between the chain tension and the soil resistance. Quantifying the normal and frictional soil resistances to the chain is required to calculate the configuration and tension profile of an embedded chain, enabling efficient anchor design according to the magnitude and inclination of the load at the padeye.

\section{Analytical solutions}

\section{System behavior:}

Solutions for the behavior of the whole length of an embedded chain in undrained soil conditions were developed by discretizing the chain into a number of arc-shaped/curvilinear elements in mechanical equilibrium with transmitted tension and soil resistance and then incrementally integrating the equilibrium equations from one end of the chain to the other. Early work by Reese (1973) discretized a weightless embedded chain as a succession of arcs of circles with varying radii, without considering the effect of frictional soil resistance on axial chain movement. The solution was improved by adding the effects of chain weight and frictional soil resistance, leading to a significant reduction of the chain tension at the anchor (Gault and Cox 1974). Vivatrat et al. (1982) considered an embedded chain as a series of curvilinear segments establishing the pair of differential equations governing respectively the variation of chain tension and geometric configuration as 


$$
\frac{d T}{d s}=F+w_{c} \sin \theta
$$

$$
T \frac{d \theta}{d s}=-Q+w_{c} \cos \theta
$$

104 where $T$ is the tension in the chain acting over the incremental chain length $d s, \theta$ is the angle

105 subtended by the chain to the horizontal, $w_{c}$ is the submerged weight of chain per unit length, and $Q$ and $F$ are respectively the normal and frictional soil resistances per unit length. The chain configuration and equilibrium of an element is illustrated in Figure 1, with boundary conditions of $T_{a}$ and $\theta_{a}$ at the padeye at depth $z_{a}$, leading to tension $T_{m}$ and $\theta_{m}$ (taken as zero here) at mudline. In general, since for most moorings $T_{m}$ and $\theta_{m}$ are specified, iteration is needed in

110 order to establish compatible values of $T_{a}$ and $\theta_{a}$. The analysis basis for embedded chains

111 proposed by Vivatrat et al. (1982) has since been adopted in many other studies (e.g.

112 Degenkamp and Dutta 1989; Dutta and Degenkamp 1989; Neubecker and Randolph 1995a;

113 Neubecker and Randolph 1995b; Neubecker and Randolph 1996).

114 The differential equations (Eqs. (1) and (2)) were solved in closed-form by neglecting the 115 weight of the chain, resulting in the tension profile (Neubecker and Randolph 1995b)

$$
\frac{T}{T_{a}}=e^{\mu\left(\theta_{a}-\theta\right)}
$$

117 with the chain friction coefficient $\mu$ defined as the ratio $F / Q$.

118 The Neubecker \& Randolph solution also established the variation of the chain angle as

$$
\frac{T_{a}}{1+\mu^{2}}\left[e^{\mu\left(\theta_{a}-\theta\right)}(\cos \theta+\mu \sin \theta)\right]_{\theta}^{\theta_{a}}=\int_{z}^{z_{a}} Q d z
$$

120 which may be simplified for small-angles as 


$$
\frac{T_{a}}{2}\left(\theta_{a}^{2}-\theta^{2}\right)=\int_{z}^{z_{a}} Q d z
$$

122 In all the above solutions, the soil resistances $Q$ and $F$, normal and parallel to the chain axis,

123 have been assumed uncoupled and fully mobilized simultaneously to the corresponding

124 ultimate capacities $Q_{u}$ and $F_{u}$.

\section{Chain-soil forces:}

126 Chains comprise multiple separate links with alternating orientations to the chain axis (Figure

127 2a) and chains of bar diameter $d_{b}$ having individual link geometries that are typically 5-6 $d_{b}$ long

128 and $\sim 3.5 d_{b}$ wide. Consequently, in order to calculate soil resistances for this complex geometry,

129 approximations about the geometry have been made by introducing an effective width of $E_{n} d_{b}$

130 for the normal resistance and effective perimeter $E_{t} d_{b}$ for frictional resistance (Reese 1973).

131 Under undrained conditions in soil with shear strength $s_{u}$, the ultimate normal resistance $Q_{u}$ and

132 frictional resistance $F_{u}$ may therefore be estimated (Degenkamp and Dutta 1989) as

$$
Q_{u}=E_{n} d_{b} N_{c} s_{u}
$$

$$
F_{u}=E_{t} d_{b} s_{u}
$$

where $N_{c}$ is the bearing capacity factor. The apparent coefficient of friction $\mu$ may be deduced from the effective width and the bearing capacity factors as $F_{u} / Q_{u}=E_{t} /\left(E_{n} N_{c}\right)$.

137 Proposed values of the effective width parameters, $E_{n}$ and $E_{t}$, and the bearing capacity factor

$138 N_{c}$ varies among researchers. The effective width of chain in bearing was first introduced by 139 Reese (1973), with an upper bound value of $E_{n}=3$ proposed by assuming that no flow of soil

140 through the opening in the chain was permitted. Vivatrat et al. (1982) adopted the bearing area

141 per unit length as the average of the maximum and minimum values, considering different

142 orientations of the chain links with respect to the soil, and the tangential area as the surface area 
of the chain link, proposing effective width parameters $E_{n}=2.6$ and $E_{t}=10$ for calculating the normal and frictional resistances per unit length, respectively. For the bearing capacity factor

145

$N_{c}$, a value equal to the ultimate lateral bearing capacity factor at depth for a pile, ranging from 9 to 11, was proposed initially (Reese 1973; Vivatrat et al. 1982). Yen and Tofani (1984) suggested that $E_{n}=2.37$ and $E_{t}=5.7 \sim 8.9$ for stud-link chains based on a series of model tests, back-calculating values of $N_{c}$ between 7.1 and 12.1. Degenkamp and Dutta (1989) quantified average values of $E_{n}$ and $E_{t}$ as 2.5 and 8.0 by investigating $6 d_{b}$ stud-link and $5 d_{b}$ studless chains with both orthogonal and diagonal configurations. The bearing factor $N_{c}$ was assumed equivalent to that of a strip foundation, increasing with depth from 5.14 at mudline to a maximum of 7.6 (Degenkamp and Dutta 1989; Dutta and Degenkamp 1989; Neubecker and Randolph 1995a; Neubecker and Randolph 1995b; Neubecker and Randolph 1996). These result in values of $\mu$ between 0.4 and 0.6 .

\section{Experimental observations and numerical simulations of embedded anchor chains}

Frankenmolen et al. (2016) reported centrifuge tests of chain-soil interaction for surface and embedded chains in carbonate sand. The chain configurations for the embedded chain under monotonic tensioning showed agreement with the analytical solutions set out in Eq. (2), except for cases where the chain formed a padeye angle greater than $70^{\circ}$. However, the back-calculated 'operative' coefficient of friction (i.e. derived from tensions and angles at the anchor and mudline using Eq. (3)) were significantly lower than obtained from the chain surface dragging tests. Partial mobilization of the frictional resistance along the embedded chain was considered one of the primary reasons.

Rocha et al. (2016) presented results of a series of chain tensioning laboratory tests in very soft clay (water contents of 100 to $120 \%$ ), including cycling of the mudline load between zero and a fixed maximum value at various mudline chain angles. At each maximum load level the deduced coefficient of friction consistent with Eq. (3), lay in the approximate range 0.2 to 0.3 . 
168 Han and Liu (2017) proposed a global yield locus for an embedded chain on the basis of data

169 from model tests on tensioning of an Omni-Max anchor in soft clay ( $s_{u} \sim 1.2$ to $\left.1.4 \mathrm{kPa}\right)$.

170 Mooring lines of both chain and rope were investigated and measured tensions at mudline and

171 anchor padeye were used to evaluate equivalent friction coefficients on the basis of Eq. (3).

172 Again, they showed that the deduced values of $\mu$ varied with progress of the test, decreasing

173 from a high value initially to steady values in the range 0.2 to 0.3 .

174 The experimental data discussed above challenge the conventional assumption in analytical

175 methods that bearing and friction are mobilized simultaneously along the entire length of the 176 chain. Explicit consideration of the bearing and shear components indicates that combined-

177 loading effects may lead to reduced friction of the chain, resulting in operative friction

178 coefficients that are significantly lower than might be estimated otherwise, for example with

179 values from model tests in clay that are about $50 \%$ of the range suggested by Degenkamp and

180 Dutta (1989).

181 Numerical investigations of the behavior of an embedded chain have been reported using the

182 Coupled Eulerian-Lagrangian (CEL) method. Pre-tensioning of an anchor chain for the 183 installation of a catenary mooring line has been examined (e.g. Kim et al. 2015; Zhao and Liu 184 2013; Zhao and Liu 2014; Zhao and Liu 2016), and the chain configuration and tension profiles 185 of the embedded chain compared with existing analytical predictions. Although discrepancies 186 between the results and the analytical tension profile of an embedded chain were noted, these 187 were not interpreted systematically, inspiring the current investigation of the chain-soil 188 interaction using CEL.

\section{Scope of present study}

190 This paper presents results of Coupled Eulerian-Lagrangian finite element analysis of the undrained response of an embedded chain in the orthogonal space of normal and frictional 
resistances. The tensioning process of the chain is modelled with a fixed anchor point ('padeye') and a horizontally loaded chain at the seabed. The chain is tensioned from the vertical 'installed' position to an equilibrium state in an inverse catenary, with gradually decreasing padeye angle as the tension is increased. Geometric configurations and tension profiles from the numerical analyses are compared with analytical predictions using the (Neubecker and Randolph 1995b) approach. Investigations of the soil resistances mobilized along the chain are presented in a yield-locus context. A method for calculating the local equivalent coefficient of friction of the embedded chain is proposed with the chain configuration established using the Neubecker \& Randolph solution and the yield locus derived from separate analyses for a deeply embedded chain. This is then extended to derive a formulation for estimating the global operative friction factor for the embedded chain system, taking account of the variation in mobilized friction along the chain length.

\section{FINITE-ELEMENT MODEL}

\section{Modelling software and approach}

All finite element analyses were carried out with the coupled Eulerian-Lagrangian (CEL) approach provided in the software Abaqus (Dassault Systèmes 2014). The basis of the CEL approach is that the element nodes move temporarily with the material during a Lagrangian calculation phase, which is followed by mapping to a spatially 'fixed' Eulerian mesh. This enables efficient simulation of large deformation problems, in this case the cutting of a mooring chain through a soil mass from an initially vertically position to form an inverse catenary.

\section{Chain geometries}

The chain was modelled as a line of equally spaced, rigid cylindrical segments, connected using 'LINK' connector elements provided as standard in Abaqus (Figure 2a). The LINK connectors 
transmit axial force but no bending moment, and maintain a fixed distance between the two connected nodes.

The length $l_{s}$ and the diameter $d_{s}$ of each segment, and the space between adjacent segments, $s_{s}$ are the three geometric variables governing the dimensions of the model chain. In the current analyses, $l_{s}$ was taken as $1 \mathrm{~m}$, with $s_{s}$ and $d_{s}$ being $0.1 \mathrm{~m}$ and $0.25 \mathrm{~m}$ respectively.

The geometries of chain in the CEL model were selected to model a standard $5 d_{b}$ studless chain as shown in Figure 2a. Each link pair of the $5 d_{b}$ studless chain was represented by one bar segment together with one spacing, i.e. the sum of $l_{s}$ and $s_{s}$ was equivalent to the length of one link pair $\left(6 d_{b}\right)$. For this model, $l_{s}+s_{s}=6 d_{b}=1.1 \mathrm{~m}$, giving $d_{b} \sim 0.18 \mathrm{~m}$. This provides a way to relate $d_{s}$ with $d_{b}$ (i.e. $d_{s} / d_{b}=0.25 / 0.18$ for this model) for the interpretation of the resistances obtained from the CEL modelling. A detailed calibration exercise is presented later in order to evaluate the numerical limiting normal and frictional resistances of the simulated chain, together with a yield locus.

The embedded chain model comprised 49 segments (giving a total length of $53.9 \mathrm{~m}$ ) as shown in Figure 2b. The padeye was set (arbitrarily) to $9 \mathrm{~m}$ below the soil surface, providing sufficient embedment to investigate the chain tensioning in a realistic manner without introducing unnecessary length (and therefore computational expense). Two chain weights of $w_{c}=0$ (weightless chain) and $1.5 \mathrm{kN} / \mathrm{m}$ were considered and the chain was loaded horizontally at the seabed (i.e. as a catenary mooring).

\section{Soil domain}

235 The soil was assumed to be fully undrained during the chain tensioning process and 236 consequently total stress analyses were performed. The undrained soil strength was assumed to 237 increase linearly with depth $z$, according to $s_{u}=2+1.2 z \mathrm{kPa}$, with the effective soil weight 238 being $2.4 \mathrm{kN} / \mathrm{m}^{3}$. These values are typical of deepwater seabed sediments offshore West Africa 
239 (Ehlers et al. 2005), which have been the focus of significant attention recently following

240 observations of anchor line trenching (Bhattacharjee et al. 2014; Colliat et al. 2018). A linear

elastic-perfectly plastic constitutive model, obeying the Tresca failure criterion, was adopted

242 for the soil. The Young's modulus $E$ was taken as $500 s_{u}$ and Poisson's ratio as 0.49 to

243 approximate incompressible soil response for undrained conditions. The regular mesh

244 comprised 8-noded linear brick elements with reduced integration (EC3D8R in the Abaqus

245 element library). A central fine mesh zone (minimum mesh size $L_{e}=0.35 d_{s}$ ) was used to

246 discretize the soil-flow area where significant soil distortion was expected due to the changing

247 chain configuration during tensioning.

\section{CEL model setup}

Figure 2b presents the global view of the CEL model (top) with the detailed chain model illustrated at the bottom of the figure. Only half of the anchor chain (with a semi-circular crosssection) and soil domain was analyzed because of symmetry with respect to the vertical plane through the chain axis. As shown in Figure 2b, the left boundary and base of the soil domain extended $7.5 l_{s}(7.5 \mathrm{~m})$ from the padeye. The length of the whole soil domain was taken as 67.6 $\mathrm{m}$, and the out-of-plane thickness as $30 d_{s}(7.5 \mathrm{~m})$ to avoid boundary effects. Above the soil surface, a layer of 'void' with height $1 l_{s}(1 \mathrm{~m})$ was prescribed, sufficient to accommodate soil heave in front of the chain during tensioning.

The anchor chain was initially 'wished-in-place' in the post-installation configuration with a

258 vertical section fully embedded and attached to the padeye, and a horizontal section laid on the 259 seabed with the centerline of the chain level with the seabed surface. Subsequently, the motion 260 of the dragging point was activated by applying a constant horizontal velocity $v_{d}$, forcing the chain to cut gradually through the soil. The dragging point was displaced horizontally until the

262 final padeye inclination angle $\theta_{a}$ reached $35^{\circ}$ to the horizontal with the dragging point located 263 sufficiently far away from the padeye to ensure that the chain remained horizontal at the 
dragging point. The response of two segments (\#13 and \#25, highlighted and numbered on

Figure 2b) was examined in post-processing to understand the chain behavior in detail.

The local coefficient of friction of the chain-soil interface was taken as 0.5 times the normal force using the 'penalty' contact option in the Abaqus library. A quasi-static solution for the tensioning process of the chain was achieved through a parametric sensitivity study of the combination of mesh density, loading velocity and coefficient of friction of the interface. Justification for the selection of a linear computational loading velocity (of $v_{d}=4.0 \mathrm{e}-5 L_{e}=$ $1.4 e-5 d_{s}$ per increment, equivalent to a velocity of $0.05 \mathrm{~m} / \mathrm{s}$ ) is shown below.

\section{Validation of the CEL model}

Prior to analyzing the embedded chain for a catenary mooring, a straight seven-segment chain was embedded horizontally at a depth of $18 d_{s}(4.5 \mathrm{~m})$ and then displaced in normal and axial directions. Comparisons of the normal and frictional soil resistances with those estimated using Eqs. (6) and (7) allowed verification of the CEL modelling, including the soil properties, chain size, interface properties, boundaries, mesh refinement and simulation velocities, consistent with those adopted in the global embedded chain model. Resultant loads on the outer two segments were excluded in the interpretation, avoiding end effects from the two ends of the seven-segment section.

A series of analyses were conducted using different input velocities $\left(8.0 \times 10^{-6}, 4.0 \times 10^{-5}, 2.0\right.$ x $10^{-4}$ and $1.0 \times 10^{-3} L_{e}$ per time increment) were conducted to quantify how the ultimate normal and frictional capacities per unit length changed with velocity due to numerical errors and therefore help select the simulation velocity. The normalized normal and frictional resistances $N_{b}=F_{N}$, sum $/ L d_{b} S_{u}$ and $N_{s}=F_{S}$, sum $/ L d_{b} S_{u}$ are shown in Figure 3 , where $F_{N \text {, sum }}$ and $F_{S \text {, sum }}$ are respectively the sums of the normal and frictional soil resistance forces on the five central 
segments of the chain, while $L$ corresponds to the total length of the central five links, i.e. $5\left(l_{s}\right.$ $\left.+s_{s}\right)$ and $s_{u}$ is the undrained strength at the depth of the chain element centroid.

Pursuing a completely convergent solution would require use of an extremely small velocity, as observed in CEL analysis of cone penetration by Wang et al. (2015), which would preclude its use in the large-domain full chain system analyses. However, the CEL results of normal and frictional capacities were comparable with the estimated values derived from Eqs. (6) and (7) using the values of $N_{c}=7.6, E_{n}=2.5$ and $E_{t}=8$ values recommended by Degenkamp and Dutta (1989). Closest agreement was obtained for the loading velocity of $4.0 \times 10^{-5} L_{e}$ per increment and so that simulation velocity was selected for the full-chain simulations (Figure 3).

Overall, the adopted simulation velocity resulted in an ultimate normal resistance value of $N_{b, \text { ult }}=Q_{u, \text { deep }} / d_{b} S_{u}=19$ (equal to the Degenkamp and Dutta (1989) recommendation), and

298 ultimate frictional resistance $N_{s, ~ u l t}=F_{u}$, deep $/ d_{b} S_{u}=6.5$ (compared to 8 from Degenkamp and Dutta (1989)). This results in an acceptable equivalent 'friction coefficient' $\mu_{p}\left(=F_{u \text {, deep }} / Q_{u \text {, deep }}\right.$ $=0.34)$, towards the lower end of the range of $0.4-0.6$ discussed earlier.

The adopted simulation velocity is about the lowest practical, given that analysis of the full chain system still required about 350 hours on a fast server. For internal consistency, all later simulations were performed applying this velocity at the chain end. While there will still be some velocity variation at different locations along the chain, the variation of the net friction coefficient is relatively minor and will not affect the validity of the conclusions reached.

\section{RESULTS}

\section{Yield loci for embedded chain segments}

The normal and tangential motion of the embedded chain induces failure of the soil as it cuts through. Consequently, before analyzing the complete chain system, a suite of numerical 
analyses were performed on the seven-segment section of chain (weightless and $w_{c}=1.5 \mathrm{kN} / \mathrm{m}$ )

for a deeply embedded (centroid depth $=18 d_{s}\left(4.5 \mathrm{~m}, s_{u}=7.4 \mathrm{kPa}\right)$ ) and a surface-laid chain the normal and frictional soil resistances interact and to develop yield loci.

The resulting interaction diagrams are shown in terms of normalized normal and frictional resistances $N_{b}$ and $N_{s}$ in Figure 4 for the two different embedment conditions. To probe the yield locus for the deep condition, displacement-controlled probes (each at a different displacement angle $\omega$ to the normal of the chain axis) were conducted (Figure 4a). A yield locus was then selected, based on the final load path sections (when the load path reaches the failure envelope and turns tangential to it) and the final points of the load paths when loads had stabilized with further displacement. The yield locus took the form of a generalized ellipse:

$$
\left(\frac{N_{b}}{N_{b, \text { ult }}}\right)^{m}+\left(\frac{N_{s}}{N_{s, \text { ult }}}\right)^{n}=1
$$

where $N_{b \text {, ult }}$ and $N_{s, \text { ult }}$ are taken as 19 and 6.5 for pure penetration and sliding (see Figure 4a) and $m$ and $n$ are fitting parameters. The exponents $m$ and $n$ of the yield locus function were selected as 2.0 and 2.3, which are close to those proposed by Han and Liu (2017). Furthermore, separate analyses revealed that the shape factors $m$ and $n$ remain consistent for different gradients of the soil shear strength. Also from Figure 4a, normality is shown to apply for the 327 yield locus of the deeply embedded section, with the plastic displacement ratio of the chain consistent with the gradient of the yield locus. In this way, the resistance ratio F/Q during failure of the soil around the chain is related to the kinematics of the chain.

Although the above envelope does not fit the numerical data perfectly (for example, it cannot capture discontinuous changes in mechanisms around the envelope), it is simple and easily implementable in design. Given that each point along the chain is at a different point on the 
envelope, this is likely to mean that minor disparities are insignificant, and consequently, we consider that the approach is sufficiently accurate for design purposes.

For the surficial chain segments, it was found difficult to probe the yield locus with a displacement-controlled scheme. Instead, the $Q-F$ yield locus was deduced using loadcontrolled analyses. The load paths are shown in Figure 4b with the final point on each line representing 'failure' (i.e. a point where increasing displacement does not change the mobilized resistance). The resulting envelope is a chili-leaf-shaped locus, with no frictional resistance when the normal force is zero because the chain is weightless. The shape of the locus near the original reflects the contact with a frictional coefficient of 0.5 adopted in the CEL model for the chain-soil contact interface.

A comparison between the yield loci for $w_{c}=0$ and $1.5 \mathrm{kN} / \mathrm{m}$ is presented in Figure 5. The difference between the normal capacities of the weightless and weighty chains is simply $w_{c} / d_{b} S_{u}$. Both yield loci show greater interaction effects than those for a suction caisson (Aubeny et al. 2003).

\section{Global chain analyses}

Figure 6 presents the development of padeye angle $\theta_{a}$ and tensions at mudline $T_{m}$ and padeye

$349 T_{a}$ as the chain is dragged. The padeye angle remained at $90^{\circ}$ until a significant displacement, approximately $3.5 \mathrm{~m}$, was imposed at the dragging point, and then decreased almost linearly as the dragging distance increased to the target $6.4 \mathrm{~m}$. The delay in change of $\theta_{a}$ reflects the gradually developing catenary profile, with parts of the chain at shallow depth cutting through

353 the soil much earlier than the chain near the attachment point. The tensions develop linearly initially, but with a gradually increasing rate as the chain becomes taut. Minimal chain-weight effect is shown when comparing the results of weightless and weighty chains, apart from slight divergence of the tension responses at a large dragging distance. 
The relationships between padeye angle and chain tension are shown in Figure 7, comparing the results with the analytical solutions of Neubecker \& Randolph (1995b). Although good agreement is evident for the response at the anchor padeye $\left(T_{a}-\theta_{a}\right)$, the analytical solutions indicate higher values of $T_{m}$ for a given padeye angle than obtained from the CEL analyses. This is discussed in more detail later.

Figure 8 compares the configurations of the embedded chain obtained from the CEL analyses for selected chain inclination angles at the padeye $\left(\theta_{a}\right)$ during the tensioning process. The CEL results of the chain profiles agree well with the analytical predictions derived from Eq. (4) with $Q=Q_{u, \text { deep }}=19 d_{b} S_{u}$ and $\mu=\mu_{p}=0.34$, indicating the robustness of the Neubecker $\&$ Randolph relationships. It appears reasonable to use $Q_{u \text {, deep }}$ at all depths in Eq. (4) rather than adjust it to allow for the decrease at shallow embedment. This reflects the small contribution of resistance for the shallowly embedded part of the chain compared with the integrated resistance of the whole chain. The additional embedment due to the chain weight is minimal in proximity to the mudline (Figure 8b), reflecting the relatively low self-weight generated bearing pressure of the chain ( $w_{c} / d_{b} S_{u}=4.2$ for the mudline shear strength of $2 \mathrm{kPa}$ ) compared with a limiting bearing factor of over 12 (see Figure 4b).

The CEL results of the tension ratio $T_{a} / T_{m}$ as a function of the decreasing padeye angle are compared with analytical predictions in Figure 9a for the weightless chain. A gradual increase of the tension ratio with increasing $\theta_{a}$ is shown for both CEL results and the Neubecker \& Randolph predictions by Eq. (3). However, the tension ratio obtained from the CEL analysis is significantly higher than the predictions by Eq. (3), e.g. CEL gives $T_{a} / T_{m}=0.90$ for $\theta_{a}=75^{\circ}$, compared with 0.65 by Eq. (3) (Figure 9a).

The depth profiles of normalized tension $T / T_{a}$ in the chain are shown in Figure $9 \mathrm{~b}$ for the final padeye angle of $\theta_{a}=35^{\circ}$ and chain weights of $w_{c}=0$ and $1.5 \mathrm{kN} / \mathrm{m}$. The CEL results show 
much smaller exponential increases with distance from the padeye compared with the analytical predictions consistent with the increased $T_{a} / T_{m}$ ratios discussed above.

To globally re-evaluate the 'operative' coefficient of friction over the full length of the embedded chain by Eq. (3), the CEL results of the tension ratio $T_{a} / T_{m}$ as a function of the dragging distance are compared in Figure 10 against the analytical predictions derived based on the padeye angle-dragging distance relationships (Figure 6a) and Eq. (3) with varying 'operative' coefficient of friction $\mu$ values. Full mobilization of the (uncoupled) frictional resistance corresponds to the case of $\mu=\mu_{p}=0.34$. In contrast, the CEL $T_{a} / T_{m}$ results agreed with the analyses using $\mu=0.07$, indicating that only about $20 \%$ on average of the potential frictional capacity is mobilized along the embedded chain during the tensioning process. Note that the operative coefficient of friction back-figured from the $T_{a} / T_{m}$ profile does not affect agreement of the CEL and Neubecker-Randolph $T_{a^{-}} \theta_{a}$ responses (see Figure 7) since Eq. (5)

393 indicates that the chain tension at the padeye, $T_{a}$, is insensitive to the mobilized frictional 394 resistance.

The operative coefficient of friction provides a straightforward assessment of the partial 396 mobilization of the frictional resistance, even though it cannot rigorously define the mobilized 397 frictional resistance for each given anchor chain segment. This will be examined in the next 398 section.

\section{Mobilized soil resistance along the anchor chain}

400 The evolution of normalized normal and frictional soil resistances, $Q / Q_{u \text {, deep }}$ and $F / F_{u \text {, deep }}$ for 401 two representative segments (identified as 'segment \#13' and 'segment \#25') in the weightless 402 chain during tensioning is shown in Figure 11. The mobilized frictional and bearing forces for 403 these elements are compared with the yield loci derived for the surficial and deeply embedded 
chain for chain profiles (1), (2), (3) and (4), which correspond to dragging distances of 1.5, 3.0, 4.5 and 6.0 m respectively.

The evolution of the soil resistances reflects the cutting through of the chain during the tensioning process. Both segments initially slide (axially) across the seabed, with the data points for normal and tangential resistances travelling along the low $Q / Q_{u}$ segment of the locus for the surficial chain. Subsequently, the $Q-F$ states transition between the yield locus for the surficial chain and that for the deeply embedded section, corresponding to the soil failure at intermediate depths as the chain cuts progressively deeper into the soil. Finally, the $Q-F$ loading condition on each chain segment moves towards a pure bearing condition, i.e. $Q \sim Q_{u}$, deep, and $F \sim 0$, as the chain is tensioned.

The normalized normal and frictional soil resistances derived from CEL for all chain segments at the mudline $(\mathrm{z}=0)$, at intermediate depths $\left(\mathrm{z}=0\right.$ to $\left.3 d_{s}\right)$ and when deep $\left(\mathrm{z}=3 d_{s}\right.$ to $\left.z_{a}\right)$ are plotted in Figure 12 against the yield loci for surficial and deeply embedded chains at padeye angles of $\theta_{a}=75^{\circ}, 60^{\circ}, 45^{\circ}$ and $35^{\circ}$. It is evident that the $Q-F$ data for the segments embedded at depths from $3 d_{s}(0.75 \mathrm{~m})$ to $z_{a}(9 \mathrm{~m})$ lie close to the outer (deep embedment) yield locus, while those for the surficial segments lie close to the inner (surficial) locus, with some transition segments in between those two groups.

For the segments at the mudline, the operative $F / Q$ ratios (i.e. $\mu$ in analytical equations) lie just above the line of $\mu_{p}$, showing 'sliding' behavior. For the deeply embedded sections, normal resistance is close to fully mobilized $\left(Q \sim Q_{u}\right.$, deep $)$, while frictional forces are small $(F \sim 0)$, so that the friction ratio $F / Q$ is considerably smaller than $\mu_{p}$. This is attributed to the dominance of normal movement, rather than axial movement, which is restricted by the padeye and the axial stiffness of the chain. Due to the relatively small value of $Q$ near the soil surface, the global operative coefficient of friction is dominated by the $F / Q$ ratios for the deeply embedded part of the chain. 


$$
\mu_{\text {le }}=\frac{F_{\text {deep }}}{Q_{\text {deep }}}=\frac{N_{s}}{N_{b}}=\left[\frac{m}{n}\left(\frac{N_{s, u l t}}{N_{b, \text { ult }}}\right)^{n} \tan \omega\right]^{1 /(n-1)}=\left[\frac{m}{n}\left(\frac{N_{s, \text { ult }}}{N_{b, \text { ult }}}\right)^{n} \frac{\Delta u_{t}}{\Delta u_{n}}\right]^{1 /(n-1)}
$$

448 yield locus. However, it was found for the cases considered here that this made no significant 449 difference to the results compared with assuming $Q_{\text {deep }}=Q_{u \text {,deep }}$. The equation can be modified to allow for the chain weight and the chain inclination as 


$$
\mu_{l e}=\left[\frac{m}{n}\left(\frac{N_{s, u l t}+w_{c} \sin \theta / d_{b} s_{u}}{N_{b, u l t}-w_{c} \cos \theta / d_{b} s_{u}}\right)^{n} \frac{\Delta u_{t}}{\Delta u_{n}}\right]^{1 /(n-1)}
$$

The relationship between $\mu_{l e}$ and $\Delta u_{t} / \Delta u_{n}$ is therefore determined by Eqs. (9) and (10) with the shape parameters $m$ and $n$ of the yield locus for the deeply embedded chain and the resistance 454 The above equations can be used to analyze the response of the chain system in the soil as 456 follows:

Step 1: Estimate the configuration of an embedded chain for a given padeye angle $\theta_{a}$ using the 458

Step 3: Calculate the incremental displacement in the normal and tangential direction for each 462 Step 4: Calculate $\mu_{l e}$ for each chain element using Eq. (9) or (10). Step 5: Calcualte the updated mudline load and anchor padeye loads using the updated $\mu$ values. angle) is reached.

The values of $\Delta u_{t} / \Delta u_{n}$ and $\mu_{l e}$ calculated from Eq.(9) are shown on Figure 14 as a fuction of the embedment depth for selected configurations of an embedded chain with padeye angles $\theta_{a}=$ $75^{\circ}, 60^{\circ}, 45^{\circ}$ and $35^{\circ}$. The incremental displacement ratio $\Delta u_{t} / \Delta u_{n}$ at given depth $z / z_{a}$ decreases individual chain element along the embedded chain.

Step 6: Return to step 2 and loop until the final design mudline load (or a target padeye chain as padeye angle $\theta_{a}$ decreases (Figure 14(a)), reflecting a reduction of the tangential motion of 
the chain as it is tensioned. For a given padeye angle, there is a rapid increase of $\tan \omega$ from the

padeye to the mudline, because of the relaxation of the axial movement constraint when remote from the padeye. Similar to the trend of $\Delta u_{t} / \Delta u_{n}$ shown in Figure 14(a), $\mu_{l e}$ decreases as the padeye angle $\theta_{a}$ decreases, and there is a marked increase of $\mu_{l e}$ from the padeye to the soil surface (Figure 14(b)).

The values of $\mu_{l}$ derived from the proposed method are compared with the CEL results of the $F / Q$ in Figure 15 for cases of $w_{c}=0$ and $1.5 \mathrm{kN} / \mathrm{m}$. Note that segments in the vicinity of the mudline were not considered in the analysis because the shallow part of the chain only contributes a very small proportion of the overall resistance. Despite the fluctuations of the CEL results, the overall predictions by Eqs. (9) and (10) agree well with the CEL results.

The above approach can also be used to calculate the average operative coefficient of the friction $\mu_{o p}^{\text {mod }}$ assuming normal resistance is fully mobilized $\left(Q=Q_{u \text {, deep }}=19 d_{b} S_{u}\right)$ :

$$
\mu_{o p}^{\bmod }=\frac{\int_{z_{a}}^{0} \mu_{l e} Q_{u}}{\int_{z_{a}}^{0} Q_{u}}
$$

This was further examined by comparing the predictions of $T_{a} / T_{m}$ calculated by Eq.(3) adopting $\mu_{o p}^{\text {mod }}$ and constant $\mu_{o p}$ of 0.07 with the CEL results during the tensioning process as shown in Figure 16. The tension ratio calculated with $\mu_{o p}^{\text {mod }}$ shows an increase from 0.91 when $\theta_{a}=75^{\circ}$ to just under 0.98 at when $\theta_{a}=35^{\circ}$. Despite fluctuations of the CEL results, the $T_{a} / T_{m}$ values derived from $\mu_{o p}^{\bmod }$ show better agreement with the numerical results than the simple and constant $\mu_{\text {op }}=0.07$, particularly for small chain angles. This demonstrates the feasibility of the proposed method for the calculation of the equivalent frictional coefficient of the embedded chain. 


\section{CONCLUSIONS}

A series of large deformation finite element analyses using the CEL approach were conducted to investigate the interaction between chain elements and the soil during different displacement trajectories and also the global system response of a catenary anchor chain cutting through soil. The results provide new insight into the response of an anchor chain system, in particular the operative axial 'friction' along the chain. A new design method is proposed for predicting tension and angle along the inverse catenary of an embedded anchor chain.

The CEL results of the configuration of the embedded chain and the tension at the padeye showed good agreement with analytical predictions, implying the suitability of assuming that normal soil resistance is fully mobilized when performing design calculations (as previously suggested by Neubecker and Randolph (1995b)). However, the CEL results showed significantly less tension attenuation from the mudline to the padeye of the embedded chain compared to previously published design approaches. This was shown to be due to the low proportion of the potential frictional capacity that is mobilized over the embedded chain during chain cutting. Partial mobilization of the frictional resistance was shown to result from interaction between the normal and frictional soil resistances as the embedded chain cuts through the soil, with almost full normal resistance and thus low frictional resistance being mobilized through most of the embedded part of chain governed by the stationary padeye condition. Consequently, the local mobilized coefficient of friction was shown to decrease significantly with increasing depth. The global 'operative' coefficient of friction, taking account of increasing shear strength with depth, is weighted towards the chain response at depth and hence is much lower than the nominal potential friction coefficient.

Equations for yield loci for the embedded chain were obtained from the numerical results and normality was demonstrated for the embedded chain sections. This allowed development of a new method for calculating the local equivalent coefficient of friction (i.e. $F / Q$ ) at every point 
along the chain, based on the yield locus and the chain configuration, and hence the incremental displacement trajectories at each point. A formulation was also developed to estimate the global operative coefficient of friction acting along the chain, facilitating more accurate calculation of the tension variation along the embedded anchor chain. The resulting analytical approach showed good agreement with the CEL results locally and globally, confirming the potential for the approach for design of mooring systems with embedded anchor padeyes.

\section{ACKNOWLEDGEMENTS}

524 This work forms part of the activities of the Centre for Offshore Foundation Systems.

525 Established in 1997 under the Australian Research Council’s Special Research Centres Program 526 and currently supported as a node of the Australian Research Council's Centre of Excellence 527 for Geotechnical Science and Engineering (ARC grant CE110001009), and through the Fugro 528 Chair in Geotechnics, the Lloyd's Register Foundation Chair and Centre of Excellence in 529 Offshore Foundations and the Shell EMI Chair in Offshore Engineering. The first author is 530 supported with a Fugro PhD Scholarship, the second author is supported by the National Natural 531 Science Foundation of China (No. 51890915) and the fifth author is supported as the Fugro 532 Chair in Geotechnics. All the support above is gratefully acknowledged.

\section{REFERENCES}

534 Aubeny, C. P., Han, S. W., and Murff, J. D. (2003). "Inclined load capacity of suction caissons." 535 International Journal for Numerical and Analytical Methods in Geomechanics, 27(14), 12355361254.

537 Bhattacharjee, S., Majhi, S. M., Smith, D., and Garrity, R. (2014). "Serpentina FPSO Mooring 538 Integrity Issues and System Replacement: Unique Fast Track Approach." In Proc., Offshore 539 Technology Conference, Offshore Technology Conference. 
Bransby, M. F., and Randolph, M. F. (1998). "Combined loading of skirted foundations."

Géotechnique, 48(5), 637-655.

542 Colliat, J.-L., Safinus, S., Boylan, N., and Schroeder, K. (2018). "Formation and Development of Seabed Trenching from Subsea Inspection Data of Deepwater Gulf of Guinea Moorings." In

Proc., Offshore Technology Conference, Offshore Technology Conference.

Dassault Systèmes (2014). ABAQUS 6.14 Analysis User's Manual, Simulia Corp, Providence,

RI, USA.

Degenkamp, G., and Dutta, A. (1989). "Soil resistances to embedded anchor chain in soft clay." Journal of Geotechnical Engineering, 115(10), 1420-1438.

Dutta, A., and Degenkamp, G. (1989). "Behaviour of embedded mooring chains in clay during chain tensioning." In Proc., Offshore Technology Conference, Offshore Technology

Conference.

Ehlers, C. J., Chen, J., Roberts, H. H., and Lee, Y. C. (2005). "The origin of near-seafloor crust zones in deepwater." In Proc., Proc. Int. Symp. on Frontiers in Offshore Geotechnics: ISFOG, 927-934.

Frankenmolen, S. F., White, D. J., and O'Loughlin, C. D. (2016). "Chain-Soil Interaction in

Carbonate Sand." In Proc., Offshore Technology Conference, Offshore Technology

Conference.

558 Gault, J. A., and Cox, W. R. (1974). "Method for predicting geometry and load distribution in 559 an anchor chain from a single point mooring buoy to a buried anchorage." In Proc., Offshore 560 Technology Conference, Offshore Technology Conference.

561 Han, C., and Liu, J. (2017). "A modified method to estimate chain inverse catenary profile in clay based on chain equation and chain yield envelope." Applied Ocean Research, 68, 142-153.

563 Kim, Y., Hossain, M. S., and Wang, D. (2015). "Dynamically Installed Anchors: Performance 564 of embedded mooring chain profile in clay." Frontiers in Offshore Geotechnics III, Meyer, ed., 565 Taylor \& Francis Group, London, 881-886. 
Neubecker, S., and Randolph, M. (1995a). "Performance of embedded anchor chains and consequences for anchor design." In Proc., Offshore Technology Conference, Offshore Technology Conference.

Neubecker, S., and Randolph, M. (1995b). "Profile and frictional capacity of embedded anchor chains." Journal of geotechnical engineering, 121(11), 797-803.

571 Neubecker, S., and Randolph, M. (1996). "The performance of drag anchor and chain systems 572 in cohesive soil." Marine georesources \& geotechnology, 14(2), 77-96.

573 O'Neill, M. P., Bransby, M. F., and Randolph, M. F. (2003). "Drag anchor fluke soil interaction 574 in clays." Canadian Geotechnical Journal, 40(1), 78-94.

575 Randolph, M., and Gourvenec, S. (2011). Offshore geotechnical engineering, CRC Press.

576 Reese, L. C. (1973). "A design method for an anchor pile in a mooring system." In Proc., 577 Offshore Technology Conference, Offshore Technology Conference.

578 Rocha, M., Schnaid, F., Rocha, C., and Amaral, C. (2016). "Inverse catenary load attenuation 579 along embedded ground chain of mooring lines." Ocean Engineering, 122, 215-226.

580 Vivatrat, V., Valent, P. J., and Ponterio, A. A. (1982). "The influence of chain friction on anchor 581 pile design." In Proc., Offshore Technology Conference, Offshore Technology Conference.

582 Wang, D., Bienen, B., Nazem, M., Tian, Y., Zheng, J., Pucker, T., and Randolph, M. F. (2015). 583 "Large deformation finite element analyses in geotechnical engineering." Computers and 584 Geotechnics, 65, 104-114.

585 Yen, B. C., and Tofani, G. D. (1984). "Soil resistance to stud link chain." In Proc., Offshore 586 Technology Conference, Offshore Technology Conference.

587 Zhao, Y., and Liu, H. (2013). "Large deformation finite element analysis of the anchor line 588 embedded in seabed soils." In Proc., ASME 2013 32nd International Conference on Ocean, 589 Offshore and Arctic Engineering, American Society of Mechanical Engineers, 590 V006T010A024-V006T010A024. 
591 Zhao, Y., and Liu, H. (2014). "Numerical simulation of drag anchor installation by a large

592 deformation finite element technique." In Proc., ASME 2014 33rd International Conference on

593 Ocean, Offshore and Arctic Engineering, American Society of Mechanical Engineers,

594 V003T010A011-V003T010A011.

595 Zhao, Y., and Liu, H. (2016). "Numerical implementation of the installation/mooring line and

596 application to analyzing comprehensive anchor behaviors." Applied Ocean Research, 54, 101-

597114. 


\section{Figure captions}

599 Figure 1. A global embedded chain and the mechanical equilibrium of a chain element

Figure 2. CEL modelling of the embedded chain

601 Figure 3. Capacities of the embedded chain model with different penetrating/sliding velocities

602

603

604

605

606

607

608

609

610

611

612

613

614 Figure 14. Example of the calculation for the local equivalent coefficient of friction based on

615 the configurations solved by the Neubecker \& Randolph solution

616 Figure 15. Distribution of the local equivalent coefficient of friction of the chain with

617 different padeye angles

618 Figure 16. Tension ratio calculated with modified operative frictional coefficient 


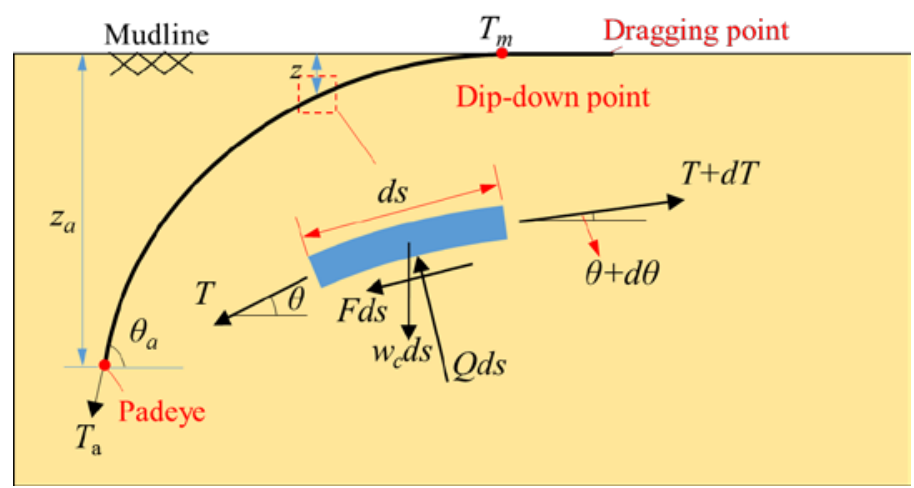

Figure 1. A global embedded chain and the mechanical equilibrium of a chain element 


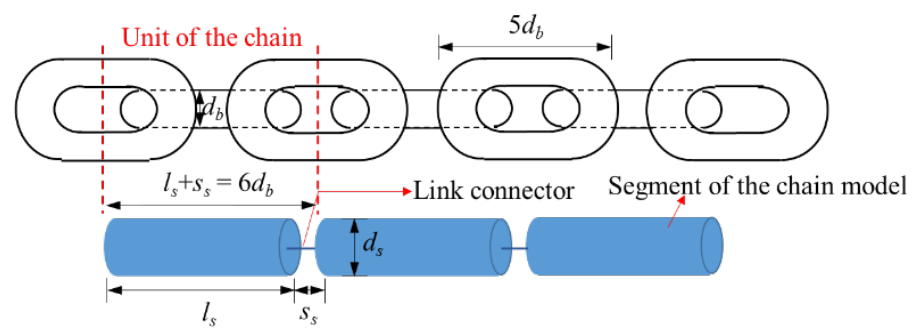

(a) Chain model corresponding to the $5 d_{b}$ studless chain
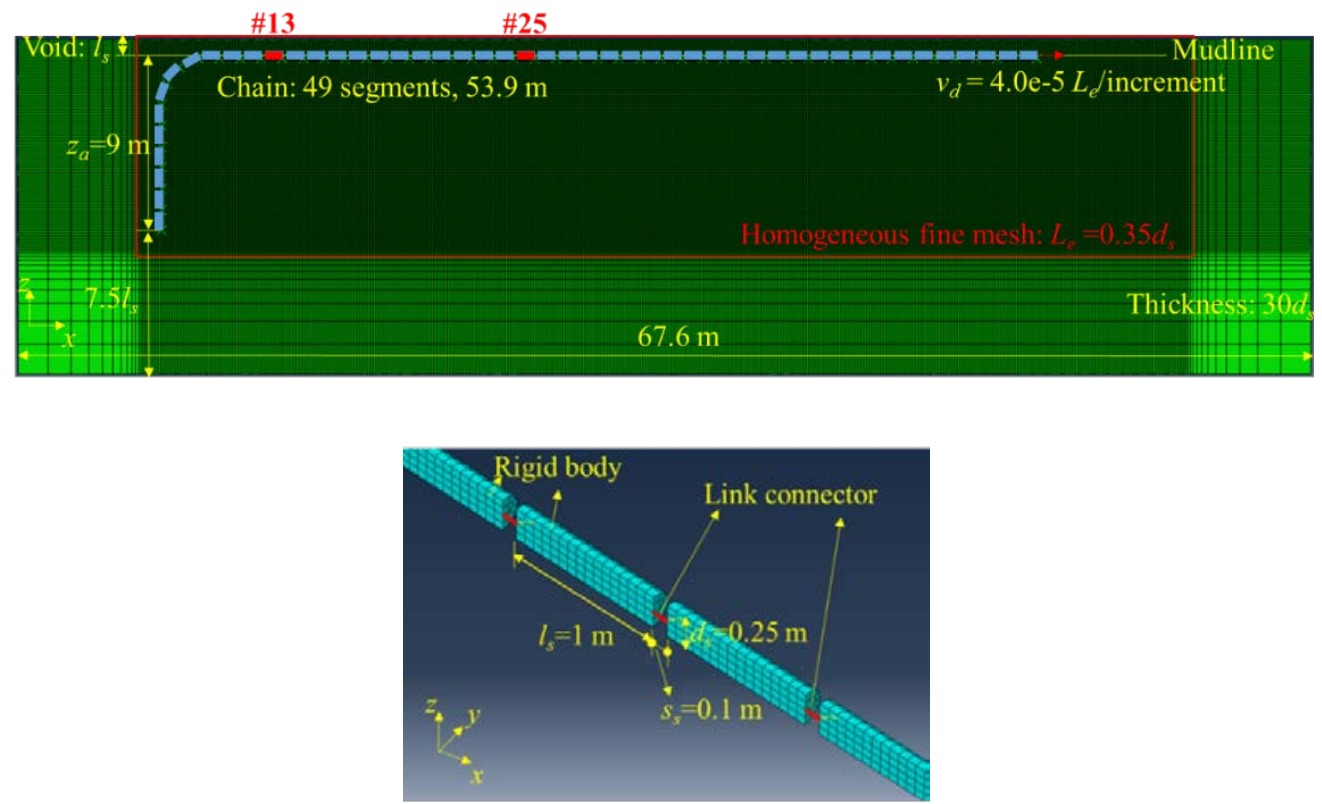


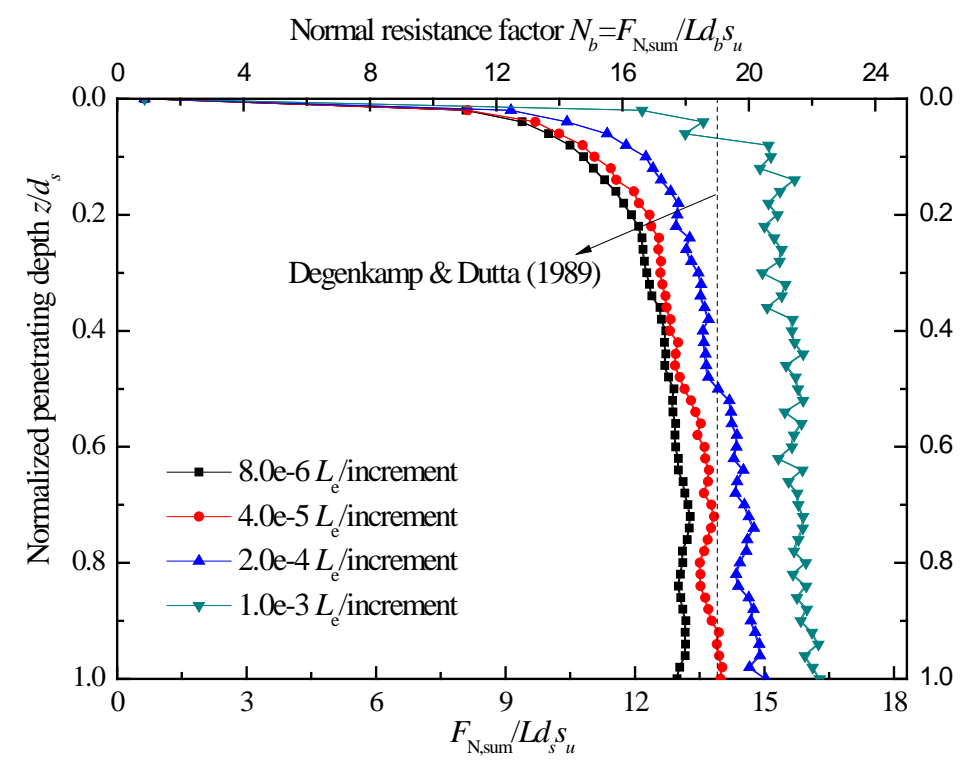

(a) Normal

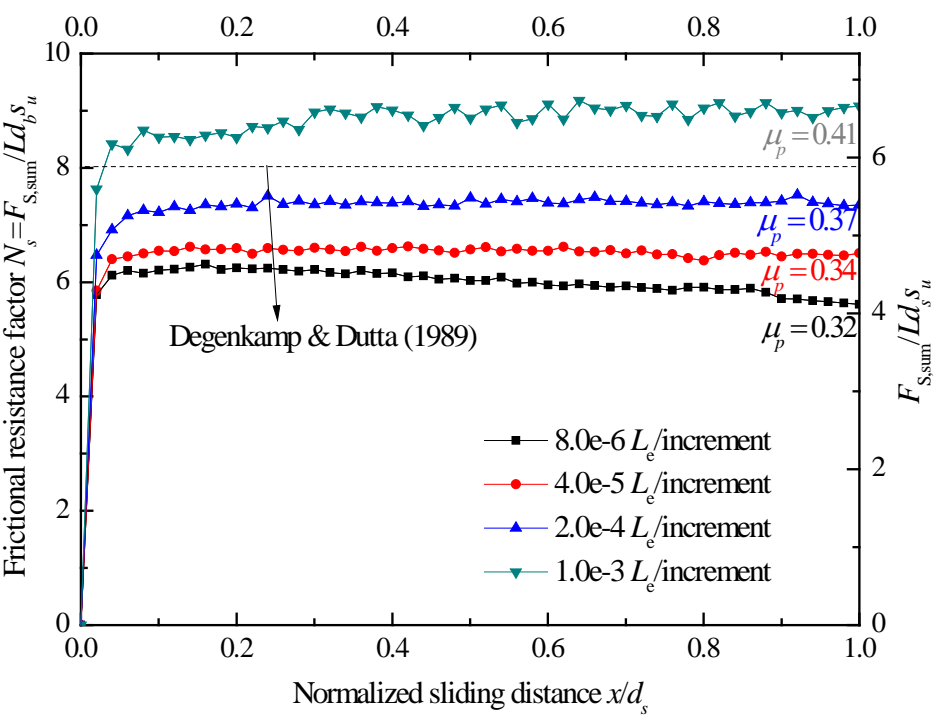

(b) Frictional

631 Figure 3. Capacities of the embedded chain model with different penetrating/sliding velocities 


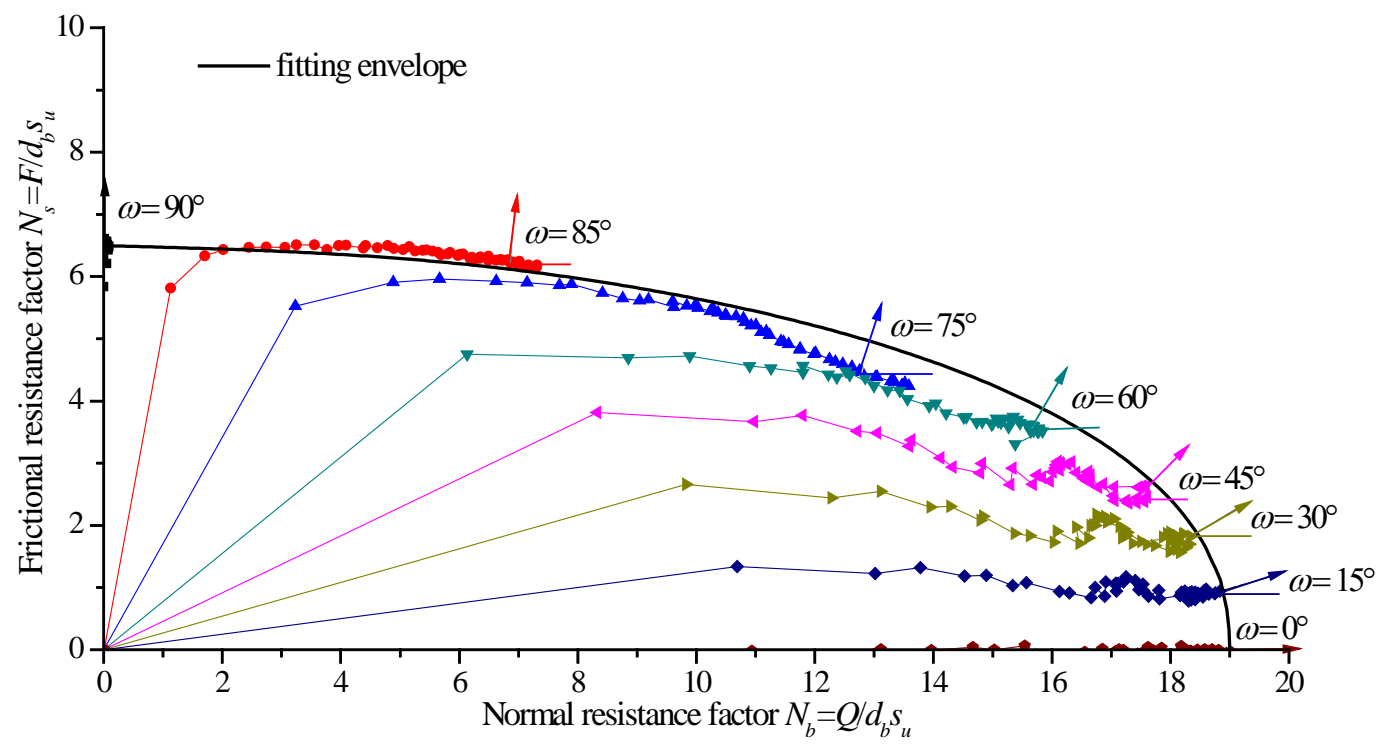

(a) Deep embedment $\left(18 d_{s}\right)$

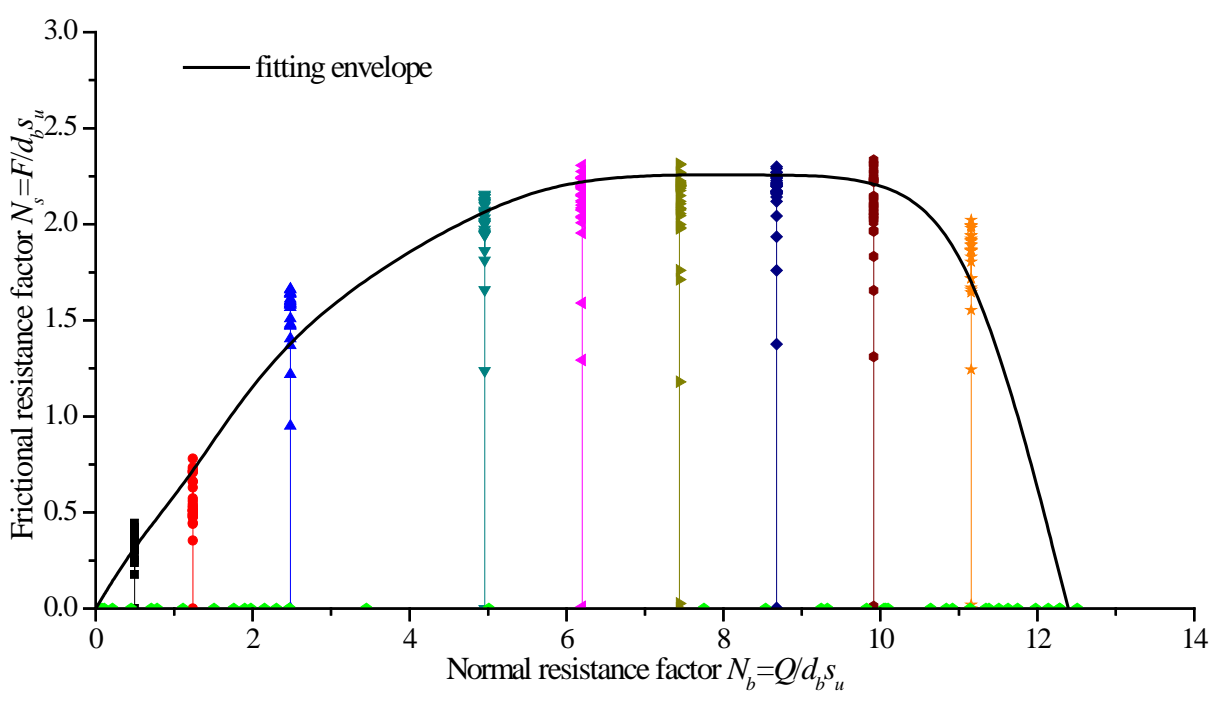

(b) Surficial

635

Figure 4. Probe testing results of the weightless chain model 


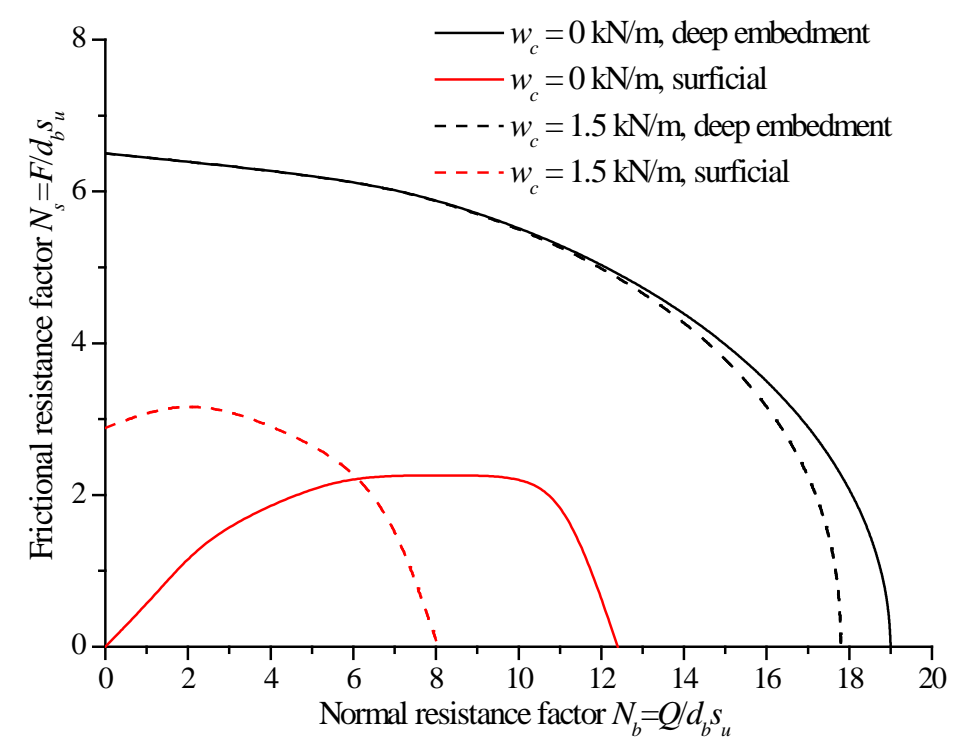

Figure 5. Yield loci of the embedded chain model 


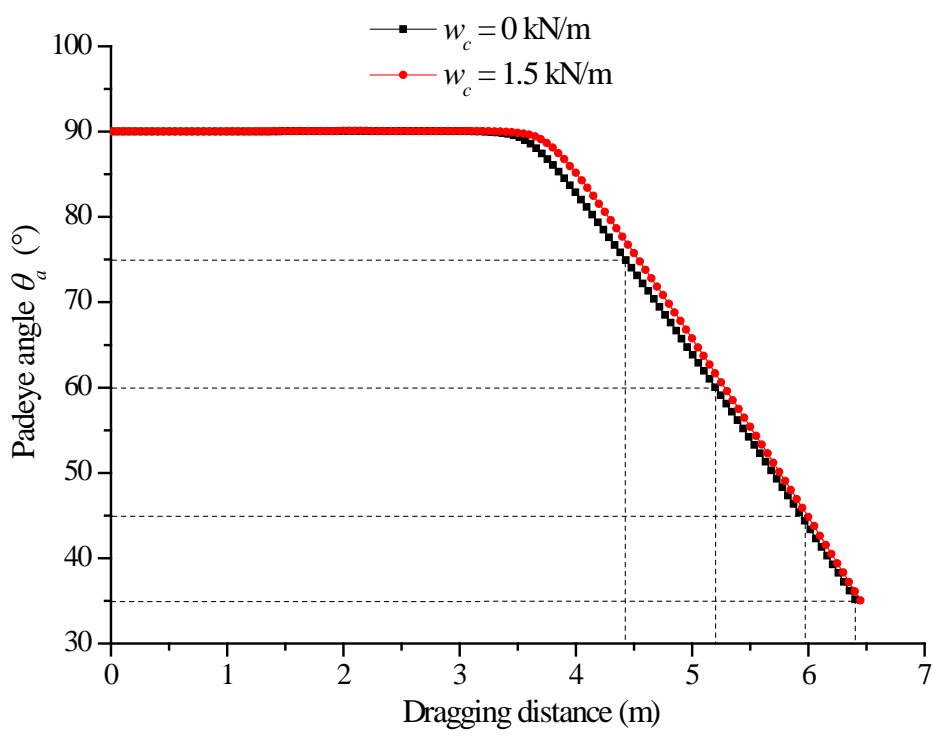

(a) Padeye angle

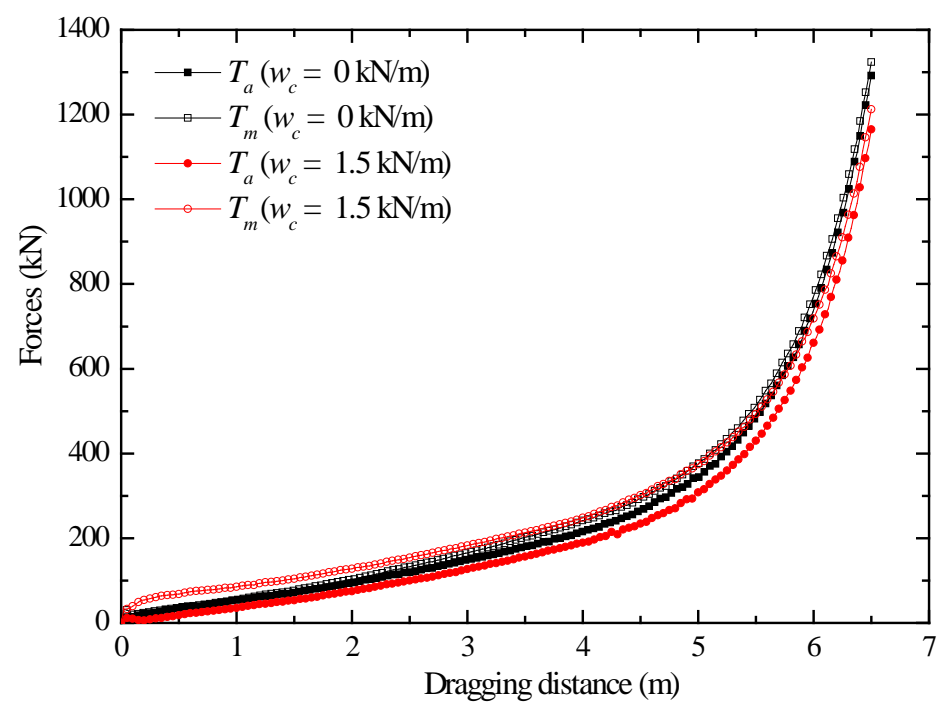

(b) Mudline and padeye tensions

643 Figure 6. Development of padeye angle and forces of the full chain system during tensioning 
644

645

646

647

648

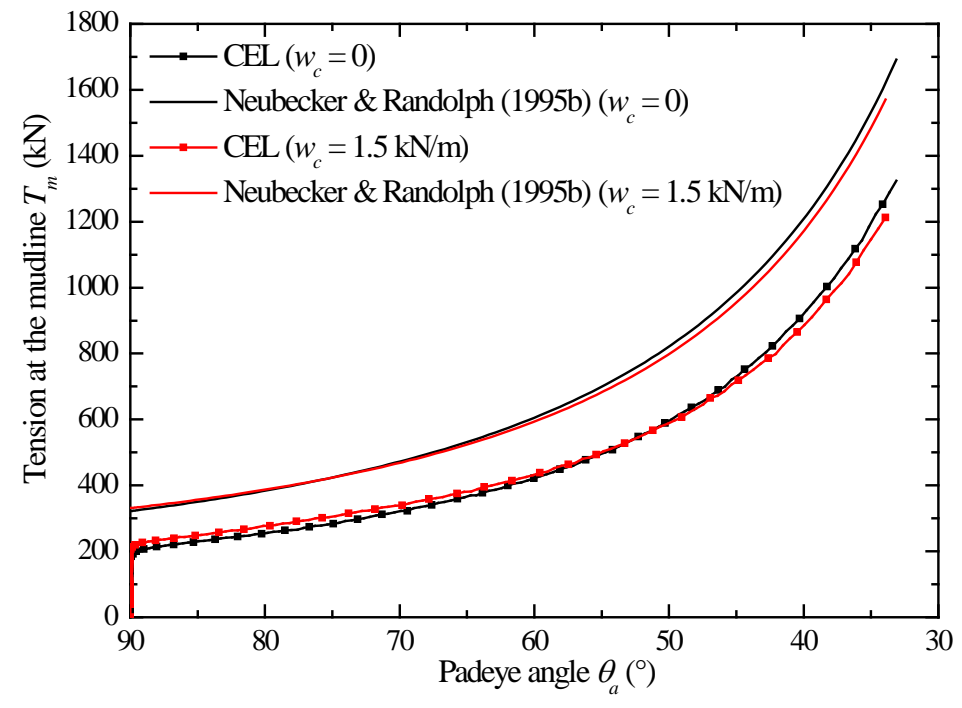

(a) Mudline tension

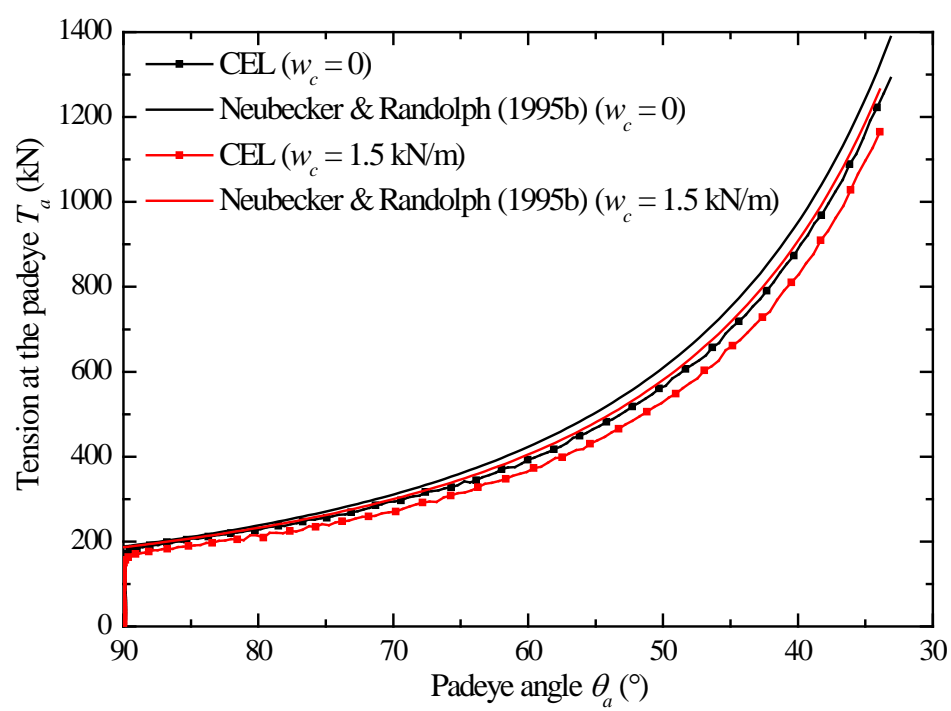

(b) Padeye tensions

Figure 7. Comparison of tension-padeye angle relationships 
649

650

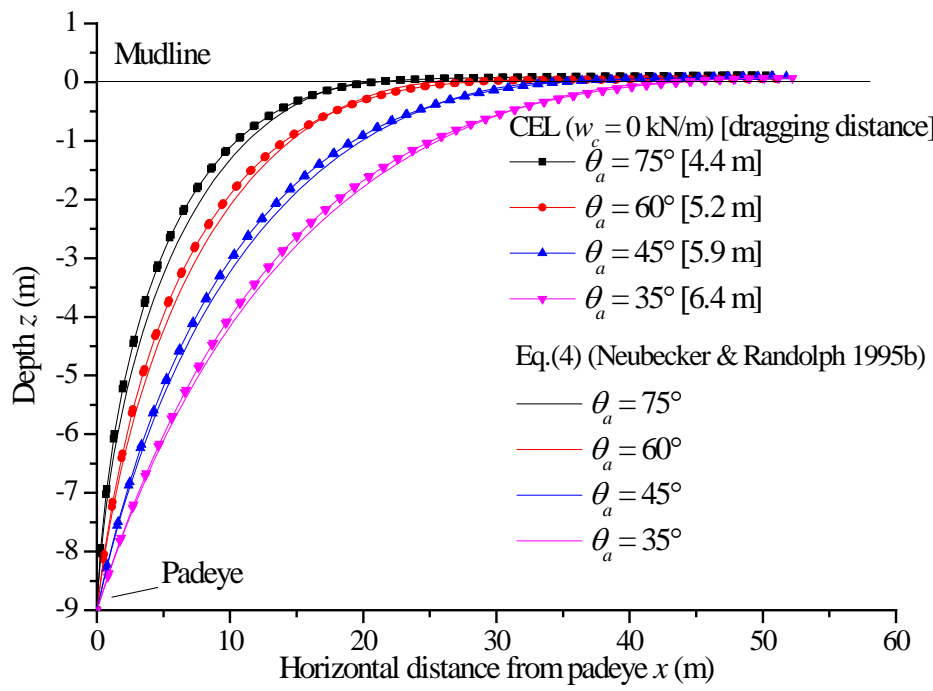

(a) $w_{c}=0 \mathrm{kN} / \mathrm{m}$

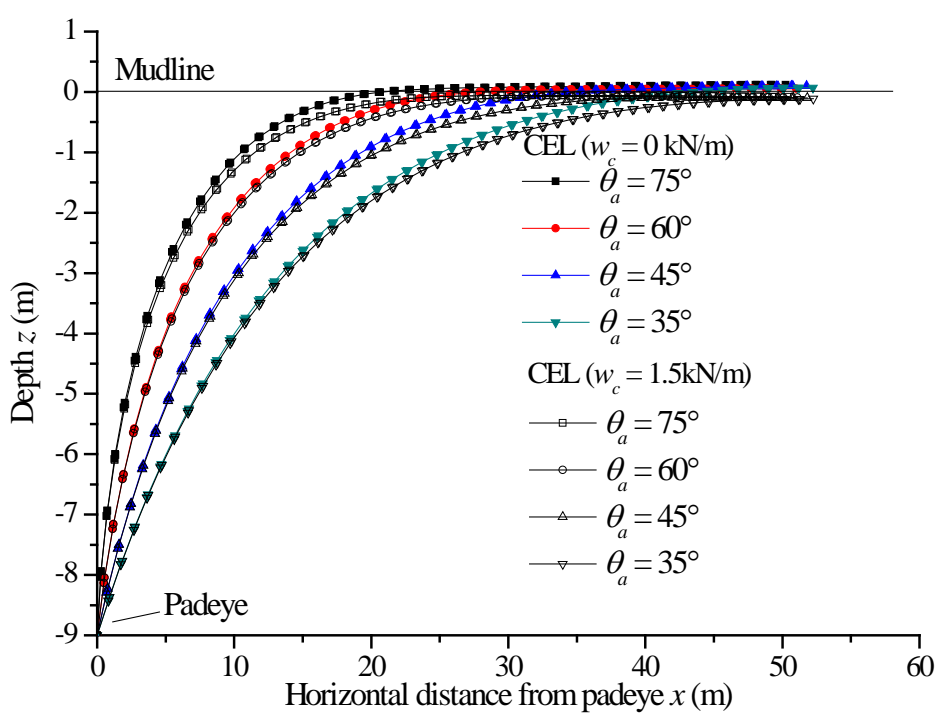

(b) Chain weight effect

Figure 8. Configurations of the embedded chain for selected chain inclination angles at the padeye during tensioning 


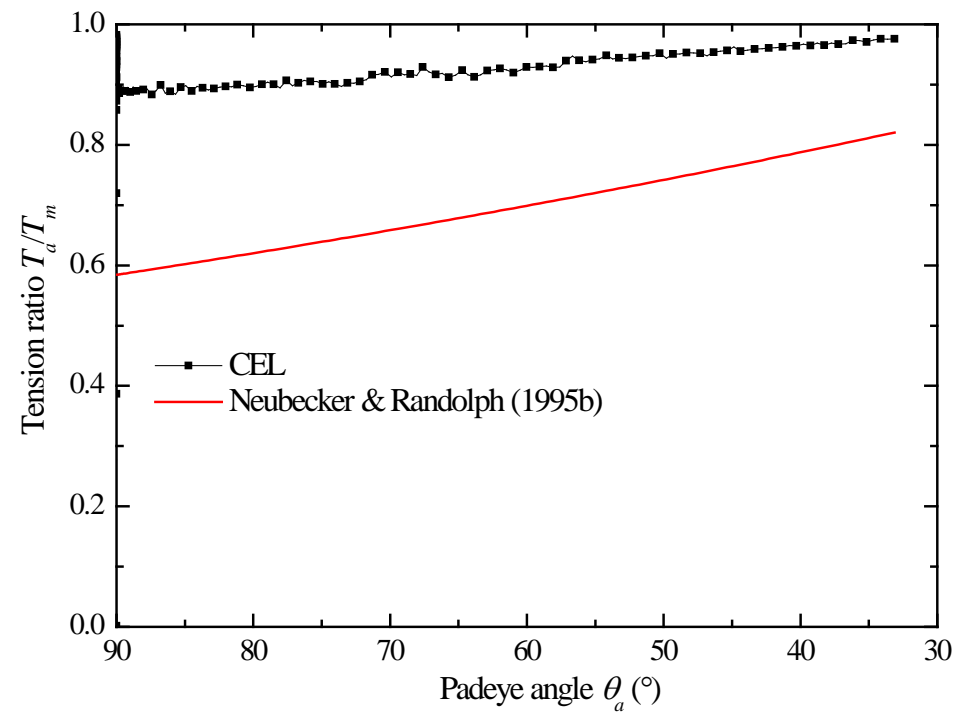

(a) Tension ratio during tensioning $\left(w_{c}=0\right)$

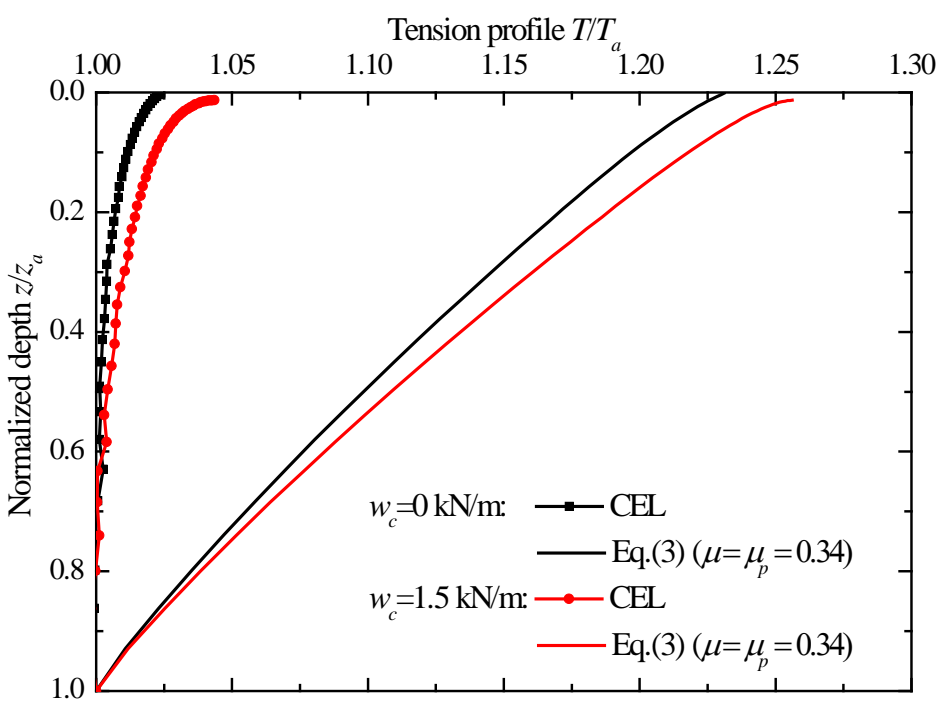

(b) Tension conditions in the chain at the padeye angle of $35^{\circ}$

Figure 9. Tension in the chain 


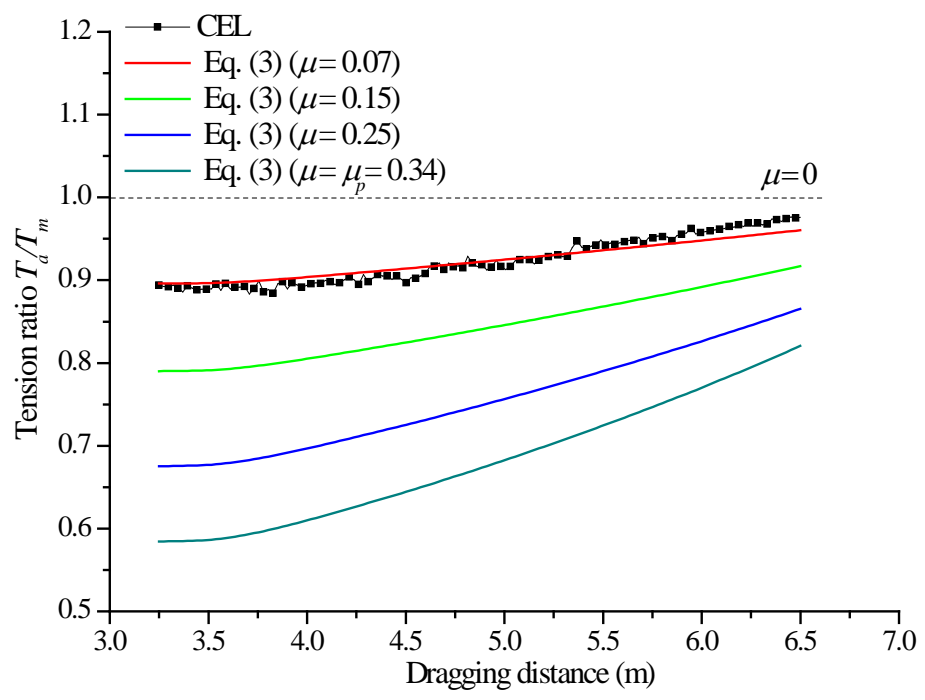




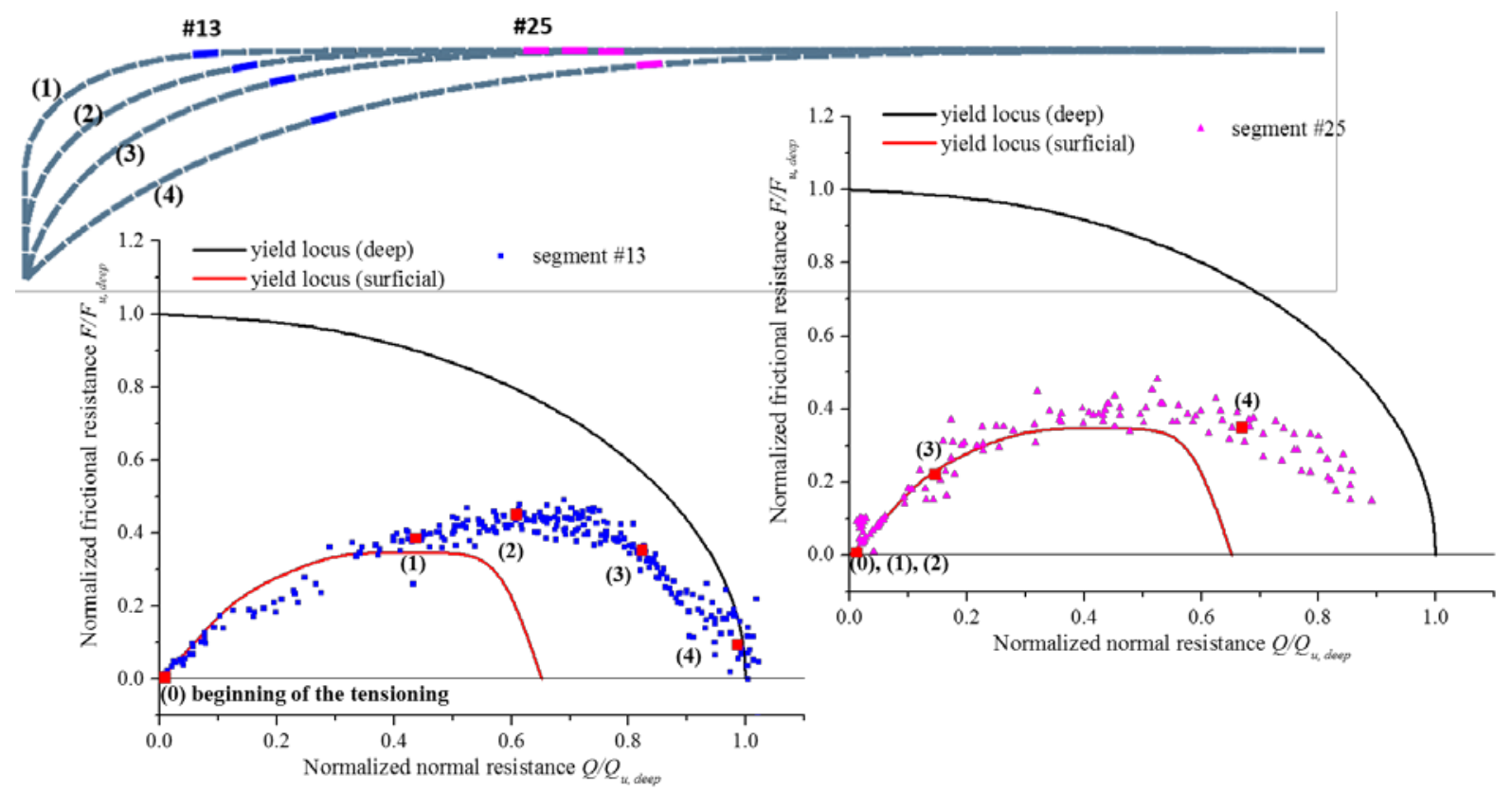

Figure 11. Evolution of the soil resistances to representative chain segments during tensioning 
666

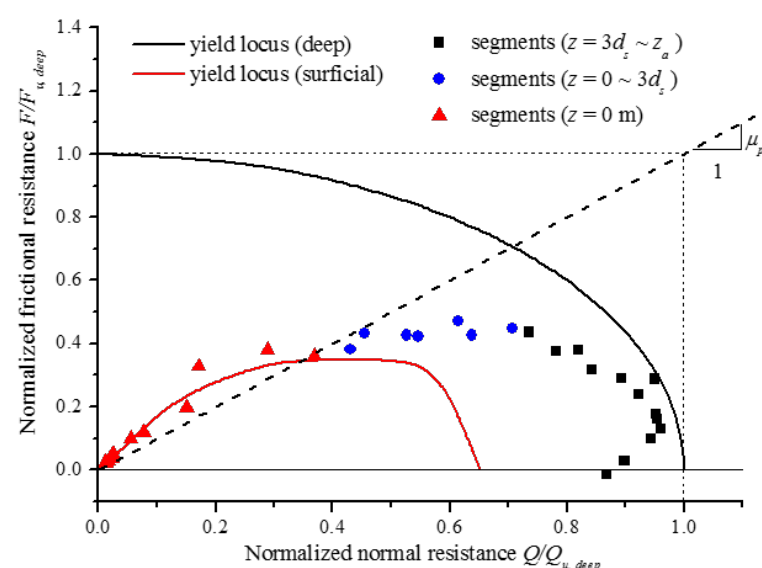

(a)

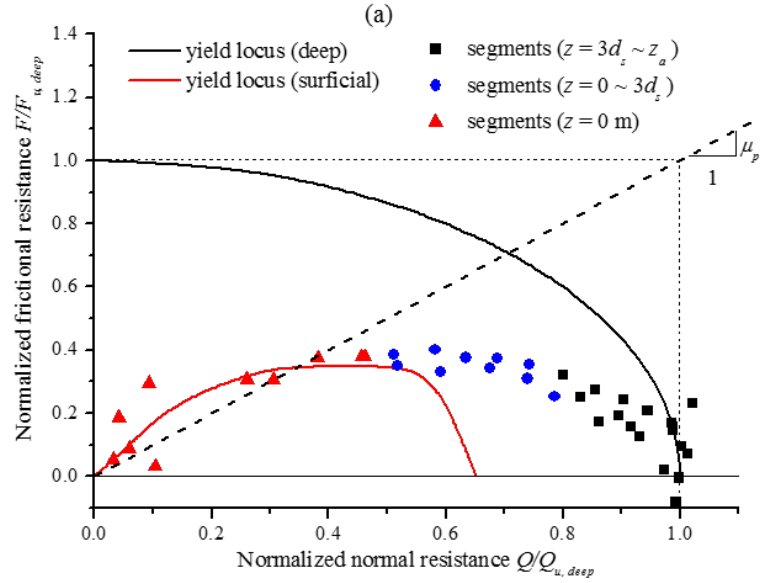

(c)

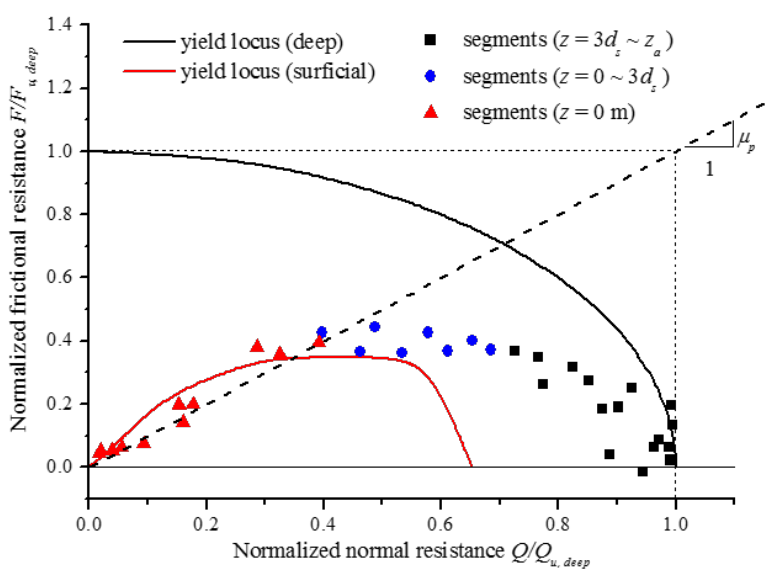

(b)

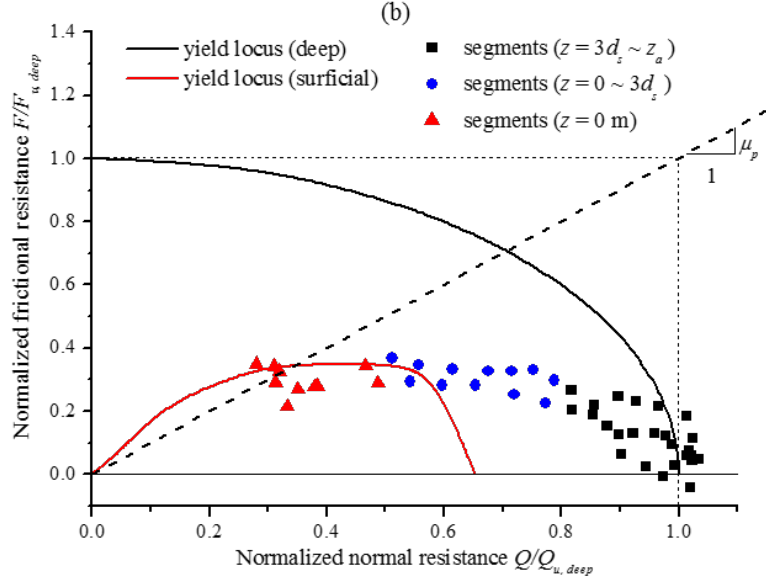

(d)

Figure 12. Distributions of the soil resistances of the embedded chain with the yield loci:

(a) $\theta_{a}=75^{\circ}$

(b) $\theta_{a}=60^{\circ}$

(c) $\theta_{a}=45^{\circ}$

(d) $\theta_{a}=35^{\circ}$ 


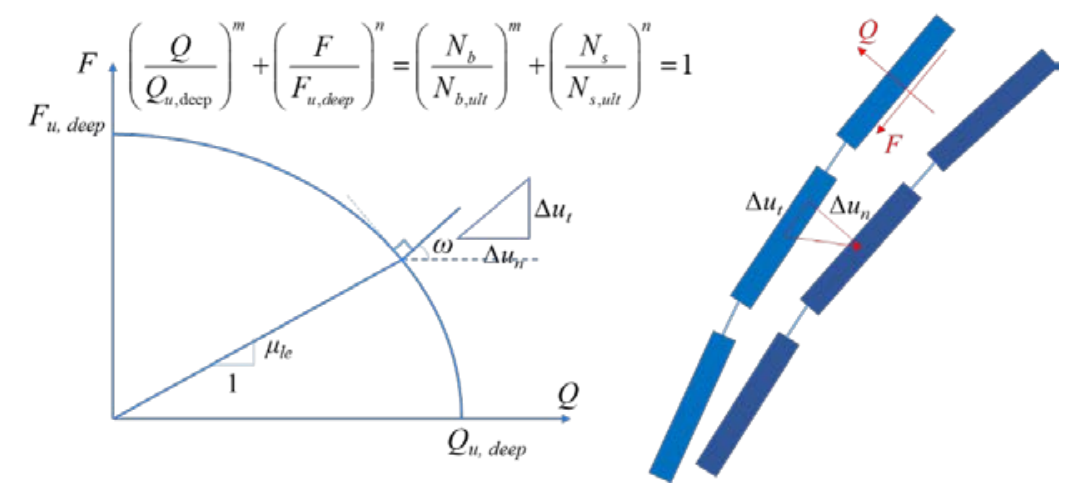

671

Figure 13. Schematic of the yield locus and the plastic potential function 


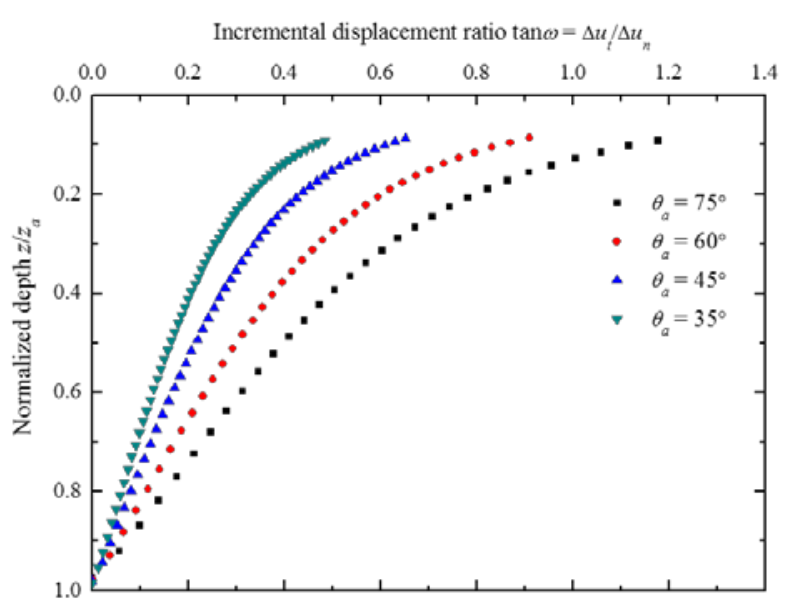

(a)

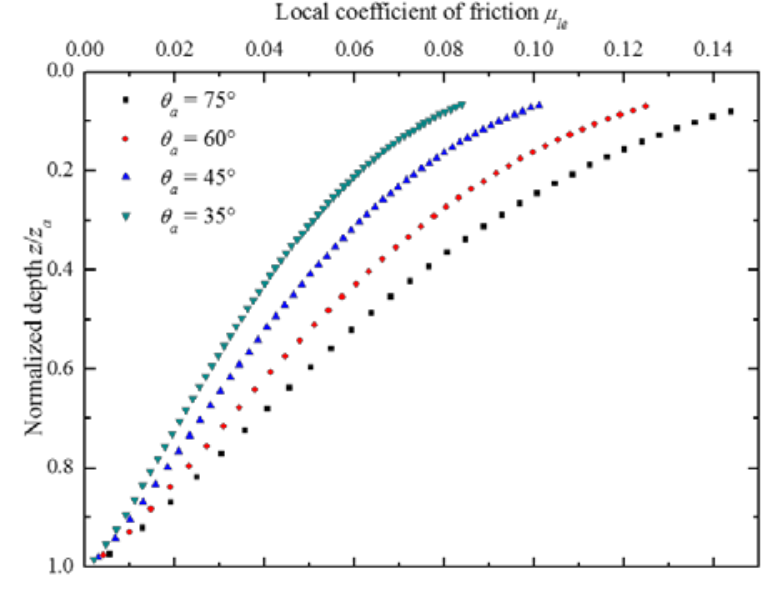

(b)

Figure 14. Example of the calculation for the local equivalent coefficient of friction based on the configurations solved by the Neubecker \& Randolph solution: (a) Incremental 

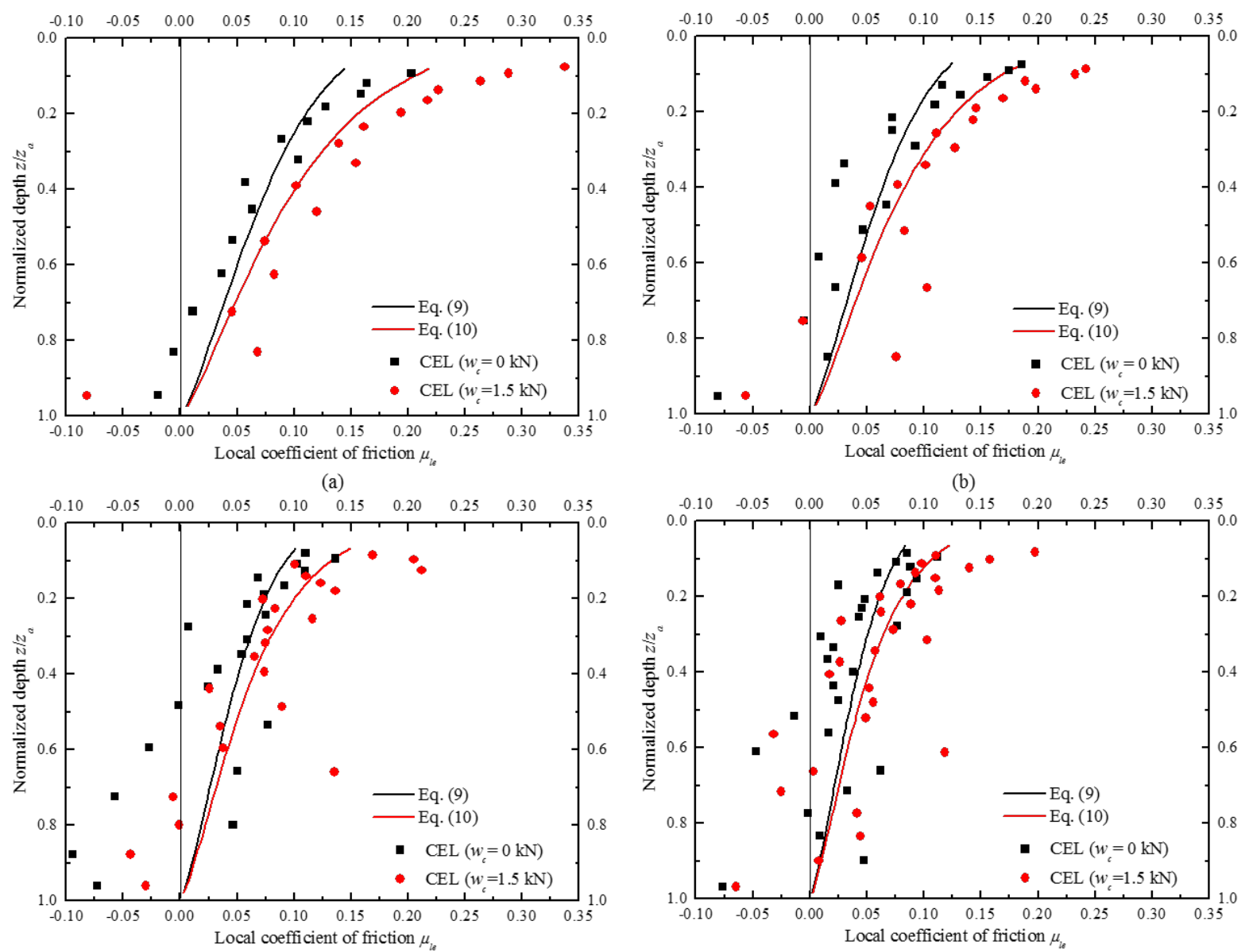

Figure 15. Distribution of the local equivalent coefficient of friction of the chain with different padeye angles: (a) $\theta_{a}=75^{\circ}$

(b) $\theta_{a}=60^{\circ}$

(c) $\theta_{a}=45^{\circ}$

(d) $\theta_{a}=35^{\circ}$ 
680

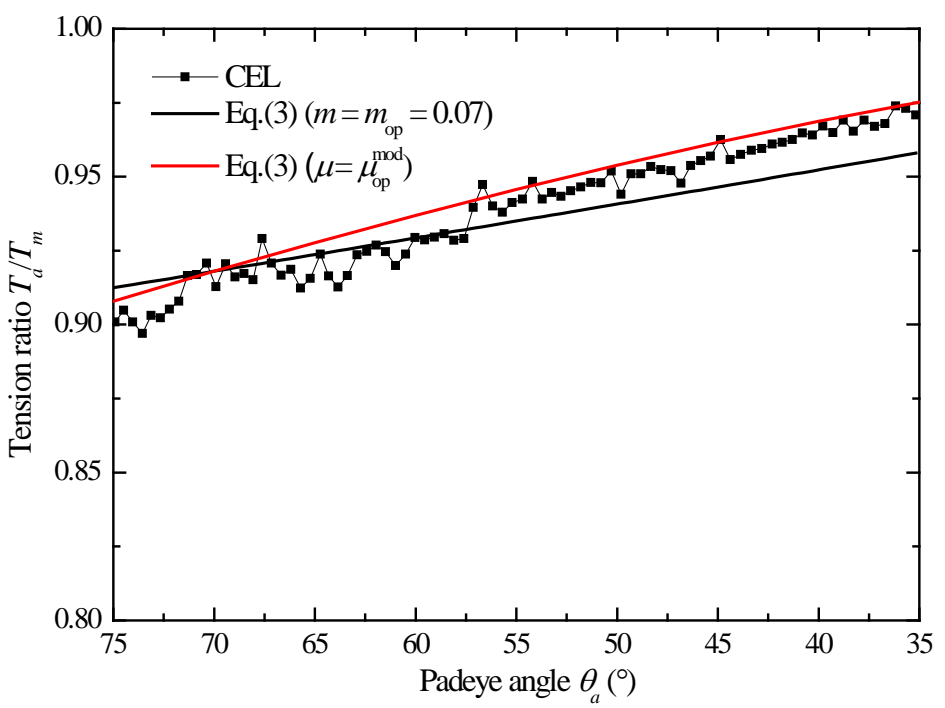

681

Figure 16. Tension ratio calculated with modified operative frictional coefficient 